\title{
Causes of Adult Blindness at ECWA Eye Hospital, Kano
}

\author{
FO Olatunji MввS, FMC(Ophth), ${ }^{1}$ S Kirupananthan FRCS (Ed), ${ }^{2}$ AA Ayanniyi MBBS, FMC(Ophth), \\ S Abuh MBBch, FWACs ${ }^{2}$ \\ ${ }^{1}$ Department of Ophthalmology, University of Ilorin Teaching Hospital, Ilorin, Nigeria \\ ${ }^{2}$ ECWA Eye Hospital, Kano, Nigeria
}

\section{SUMMARY}

Aim: To identify the cause of adult blindness at ECWA Eye Hospital, Kano.

Materials and methods: It was a hospital-based prospective study. Blindness was defined as vision of $<3 / 60$ in the better eye. The history of each patient was taken and a routine ocular examination was conducted using a Snellen or E-chart, a pen torch, a slit lamp and an ophthalmoscope. The IOP was also taken. The main causes of blindness and their primary anatomical sites were recorded.

Results: The study group comprised 622 adults; 400 were bilaterally blind while 222 were blind in one eye. The mean age of the bilaterally blind patients was 54.1 years (range 17 to 94 years). Two hundred and sixty-three (65.7\%) of the study group were male and 137 (26.3\%) were female. The most common causes of blindness were cataract, glaucoma and corneal opacity/keratitis, accounting for 162 (40.5\%), 117 $(29.3 \%)$ and $57(14.3 \%)$ of blindness respectively in the bilaterally blind. Cataract, corneal opacity/keratitis and glaucoma were the most common causes of blindness, accounting for 94 (42.3\%), 28 (12.6\%) and 19 (8.7\%) of the unilaterally blind cases.

Conclusion: Avoidable causes of blindness were predominant at ECWA Eye Hospital, Kano. Concerted efforts at increasing cataract surgical volume, awareness and early treatment of glaucoma as well as education on prevention and early treatment of corneal ulcers will markedly decrease blindness rate at the centre.

Key words: causes, adult, blindness, cataract, glaucoma, cornea

\section{INTRODUCTION}

It has been estimated that there are about 45 million blind people and 135 million visually impaired individuals the world over. ${ }^{1}$ Although the resources to combat blindness are concentrated in developed countries of the world and in urban centres, four out of every five cases of blindness occur in developing countries. ${ }^{1}$ To make matters worse, ophthalmologists are in short supply. Africa has about one ophthalmologist per million population, most of whom are situated in the capital cities and large provincial towns, whereas $80 \%$ of the population live in rural areas. ${ }^{2}$ In 1999 , the WHO Prevention of Blindness Programme launched 'VISION 2020: The Right to Sight Initiative', with the objective of assisting member states to eliminate avoidable blindness by the year $2020 .^{3}$ Globally, cataract accounts for about half of the causes of blindness, though there are regional differences in the causes of blindness. In the industrialized countries, blindness is mainly due to disorders of the posterior segment of the eye (macular degeneration and diabetic retinopathy). ${ }^{4}$ In Africa, Asia, and some parts of South America, disorders of the anterior segment of the eye (cataract, corneal scarring from various causes, and glaucoma) predominate. ${ }^{5}$

Literature on the prevalence and causes of blindness in many parts of southern Nigeria ${ }^{6-10}$ abound, only a few exist on northern Nigeria. We are aware of only one such publication on Kano State. ${ }^{11}$

The aim of this study therefore is to provide baseline information on the causes of blindness at ECWA Eye Hospital, Kano.

\section{MATERIALS AND METHODS}

This hospital-based prospective study was carried out during a routine clinical work at the ECWA Eye Hospital, Kano. The hospital is a missionary hospital in Kano; a cosmopolitan city in the northern part of Nigeria. The patients were mainly from Kano, while some were from other parts of Nigeria. The causes of blindness in consecutive patients aged 16 years or older who presented at the hospital from 1993 to 1996 and had a vision of <3/60 in one or both eyes were recorded in a protocol form.

Blindness was defined as vision of $<3 / 60$ in the better eye. Each patient had his/her history taken and visual acuity assessed using the Snellen or E-chart. Ocular examination was done using a pen torch, slit lamp, direct and indirect ophthalmoscope (when necessary), and IOP taken with either a Schiötz's or an applanation tonometer.

The main causes of blindness and their primary anatomical sites were recorded. Where multiple pathologies 
were found, the primary cause contributing to blindness at the time of presentation was recorded. One main cause was then selected for each eye. Other causes were recorded as associated causes. Attempts were made to identify the aetiology of the anatomical problems leading to blindness.

\section{RESULTS}

During the 4 years of the study, a total of 707 blind patients were seen. Six hundred and twenty-two $(88 \%)$ of them were adults. Four hundred of them were bilaterally blind while 222 were blind in one eye.

The study cohort comprised 417 male (67.0\%), and 205 female $(33.0 \%)$. The mean age was 52.8 years and the range was 16 to 94 years. Figure 1 shows the age distribution of all the patients. The most common causes of blindness in one or both eyes were: cataract $256(41.2 \%)$, corneal opacity/ keratitis $85(13.7 \%)$ and glaucoma $136(21.9 \%)$.

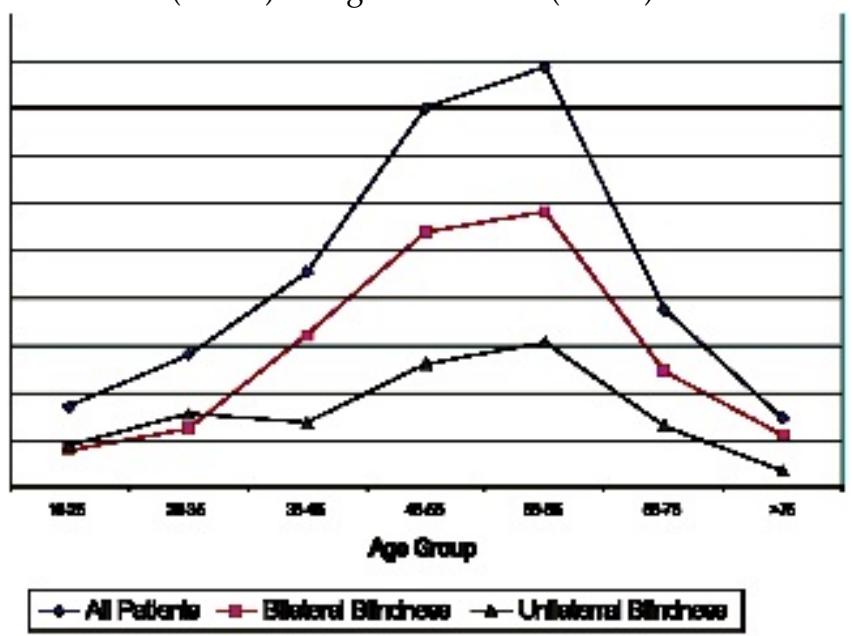

Figure 1. Age distribution of blind patients.

\section{Unilateral Blindness}

The mean age of the unilaterally blind patients was 50.4 years (range 16 to 90 years). There were 154 (69.4\%) male and $68(30.6 \%)$ female participants. Cataract, corneal opacity/keratitis and glaucoma were the most common causes accounting for $94(42.3 \%) 28(12.6 \%)$ and $19(8.7 \%)$ of the cases. Other causes are as shown in figure 2.

\section{Bilateral Blindness}

The mean age of the bilaterally blind patients was 54.1 years (ranging from 17 to 94 years). There were 263 (65.7\%) male and $137(26.3 \%)$ female participants. The most common causes of blindness were cataract, glaucoma and corneal opacity / keratitis accounting for 162 (40.5\%), 117 (29.3\%) and $57(14.3 \%)$ of blindness respectively. Other causes are shown in figure 2.
The highest rate of blindness $(28.5 \%)$ was found in the 56-65 years age group in both the unilaterally and bilaterally blind patients (figure 2).

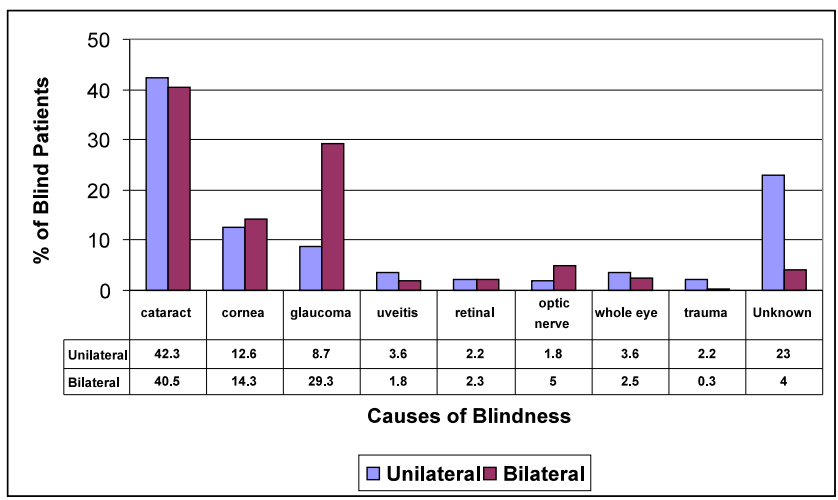

Figure 2. Causes of blindness

Causes of corneal opacity included trachoma detected in 14 patients, trauma in 5 patients, and harmful traditional practices in 3 patients. The causes in the remaining patients dated back to their childhood, probably due to measles and vitamin A deficiency.

\section{DISCUSSION}

There is substantial regional diversity in climate, social norms as well as health indicators across Nigeria. These impact on disease patterns in different regions. Some ophthalmic diseases that are common in the northern part of Nigeria are not common in the southern part of the country. ${ }^{6,12,13}$ Although substantial literature exists on the prevalence and causes of eye disease in the south; only a few studies have been carried out in the north. This informed the collection and analysis of data between 1993 and 1996 to serve as baseline information.

The mean age of 54.1 years, found in the bilaterally blind patients, is similar to the findings of other researchers ${ }^{6,8}$ in the country. The high rate of blindness found among the patients in the 56 to 65 years age group is also similar to the findings in a previous work ${ }^{6}$ but is at variance with the findings of other studies. ${ }^{8}$

Our findings revealed that blindness is more common among the male subjects $(67.0 \%)$, compared with $33 \%$ in female participants $(33.0 \%)$. This agrees with the findings of Adegbehingbe et al. ${ }^{10}$ in a community-based study, but is at variance with the findings of other workers who found equal sex distribution in a community-based study ${ }^{6}$ and in an outpatient setting. ${ }^{8}$

These findings are at variance with the generally reported gender distribution ${ }^{14,15}$ that the rate of blindness among female patients is higher than that of the male patients. This may be due to higher hospital attendance rate by men. 
The causes of blindness in the patients depict the typical scenario in developing economies where preventable or treatable causes predominate.

As found in the present study, cataract is the most common cause of bilateral and unilateral blindness. Cataract was found to be the most common cause of blindness by workers in Nigeria, ${ }^{6-11}$ in other regions of Africa ${ }^{16-20}$ and in developing countries. ${ }^{21}$ This differs from the findings in industrialized countries, ${ }^{26,27}$ where posterior segment causes such as optic atrophy, myopic macular degeneration or retinitis pigmentosa were the leading causes of blindness.

A reduction in the occurrence of cataract blindness could be facilitated by improvements in overall eye care delivery and increased rate of cataract surgery. Cataract surgical rate (CSR) in Africa is the lowest compared with the rest of the world. ${ }^{28}$ This rate can be increased by removing the barriers to cataract surgery, such as distance and costs as well as increased awareness of the availability and benefits of surgery. Community health workers should be employed in the rural areas to perform simple vision tests and ophthalmologists should be encouraged to participate in community outreach programmes. Community groups, philanthropists and donor organizations should also be urged to sponsor indigent patients.

Glaucoma was the second most common cause of bilateral blindness and the third most common cause of unilateral blindness found in the study. Oluleye ${ }^{8}$ and Dawodu' found glaucoma to be the second most common causes of both unilateral and bilateral blindness. It was the third most common cause of blindness in a community study in Kano, ${ }^{19}$ due probably to high prevalence of trachoma in the area.

There are many challenges to the prevention of blindness from glaucoma. These include lack of awareness of the disease, lack of a simple screening test, poor acceptance of surgical treatment, and lack of visual recovery after treatment. The peculiar problems in our environment are: limited access to varieties of medications for glaucoma treatment and late presentation. Poor awareness of glaucoma is a global problem. ${ }^{29,30}$ Measures to control blindness from glaucoma include:

1. identifying opportunities for diagnosing glaucoma, such as examination of patients at the time of refraction testing, before or after cataract surgery and the relatives of glaucoma patients who accompany them to the clinic for treatment

2. ensuring that glaucoma screening is part of regular eye checks, particularly for persons at increased risk, such as those with a positive family history, advanced age or ethnicity

3. ensuring that eye-care units are adequately equipped for the diagnosis and treatment of glaucoma.
4. ensuring that effective, low-cost eye drops are available for lowering intraocular pressure

5. strengthening advocacy and awareness targeting the public, eye health-care professionals and policy-makers about glaucoma and the risk for visual loss if it is undiagnosed and untreated

6. strengthening human resource development, with adequate training in the diagnosis and management of glaucoma.

Corneal reasons were the third most common cause of bilateral and the second most common causes of unilateral blindness. Dawodu and the workers in Taiwan ${ }^{17}$ and Sudan ${ }^{21}$ found corneal reasons to be the third most common cause of blindness.

The epidemiology of corneal blindness is diverse and highly dependent on the ocular diseases that are endemic in each geographical area. The main diseases which cause corneal blindness are trachoma, xerophthalmia, measles, corneal ulcerations and keratitis, onchocercosis, ophthalmia neonatorum, leprosy, injuries and harmful therapeutic practices. Risk groups are small children, isolated rural communities, unhealthy urban communities, out of place populations, and under-fed populations. Treatment of ulceration and opacity is very challenging. Antibiotic and antifungal treatment for microbial keratitis is relatively costly and the visual outcome is almost invariably poor. In many developing countries antifungal medications are not available at any price. As in the case of corneal blindness due to trachoma, a corneal transplant in the scarred vascularized tissue that follows a severe corneal infection is rarely successful. Because of the difficulty of treating corneal blindness once it has occurred, public health prevention programmes are the most cost-effective means of reducing corneal blindness. This can be achieved through individual and collective hygiene measures. Early institution of therapeutic measures, vaccination against measles, improvement of maternal and child care, and sanitation as well as nutrition education.

Cases of refractive errors were not found in this study because refractive error was not an entity recognized as a cause of blindness at the time of data collection for this study. Moreover, refractive errors more often lead to visual impairment rather than blindness.

\section{CONCLUSION}

Avoidable causes of blindness are predominant among eye patients at ECWA Eye Hospital, Kano. Concerted efforts at increasing cataract surgical volume, promoting awareness and early treatment of glaucoma as well as education on prevention and early treatment of corneal ulcers will markedly decrease blindness rate at the centre. 


\section{REFERENCES}

1. World Health Organization. Programme for the Prevention of Blindness and Deafness. Global initiative for the elimination of avoidable blindness. Geneva: WHO, 1997:1-7.

2. Johnson GJ, Foster A. Training in community ophthalmology. Ophthalmology International 1990;14:221-6.

3. Thylefors B (1998) A global initiative for the elimination of avoidable blindness. Am J Ophthalmol 125: 90-93.

4. Cotter S A, Varma R, Ying-Lai M, Los Angeles Latino Eye Study Group, et al. Causes of low vision and blindness in adult Latinos: the Los Angeles Latino Eye Study. Ophthalmology 2006;113 (9) :1574-82.

5. Foster A. Patterns of blindness. In: Tasman W, Jaeger E, eds. Duane's Clinical Ophthalmology Vol5. Philadelphia: Lippincott, 1991: 1-7.

6. Ezepue UF. Magnitude and causes of blindness and low vision in Anambra State of Nigeria (results of 1992 point prevalence survey). Public Health 1997; 111(5): 305-9.

7. Adeoti CO. Prevalence and causes of blindness in a tropical African population. West Afr J Med 2004;23(3):249-52.

8. Oluleye TS, Ajaiyeoba AI, Akinwale MO, Olusanya BA Causes of blindness in southwestern Nigeria: a general hospital clinic study. Eur J Ophthalmol. 2006; 16(4):604-7.

9. Dawodu OA, Osahon AI, Emifoniye E. Prevalence and causes of blindness in Otibhor Okhae Teaching Hospital, Irrua, Edo State, Nigeria. Ophthalmic Epidemiol 2003; 10(5): 323-30.

10. Adegbehingbe BO, Fajemilehin BR, Ojofeitimi EO, Bisiriyu LA. Blindness and visual impairment among the elderly in Ife-Ijesha zone of Osun State, Nigeria. Indian J Ophthalmol 2006; 54(1): 59-62.

11. Abdu L. Prevalence and causes of blindness and low vision in Dambatta Local Government Area, Kano State, Nigeria. Niger J Med 2002; 11(3): 108-12.

12. Kietzman B. Endophthalmitis in Nigerian children. Am J Ophthalmol 1968; 65: 211-20.

13. Rabiu MM, Kyari F. Vitamin A deficiency in Nigeria. Niger J Med 2002; 11(1): 6-8. [PubMed].

14. World Health Organization. Magnitude and causes of visual impairment. WHO Fact Sheet $\mathrm{N}^{\circ} 282$ - November 2004

15. Susan L, Paul C. Blindness in Africa. Br J Ophthalmol 2001; 85: 897-903.

16. Oye JE, Kuper H. Prevalence and causes of blindness and visual impairment in Limbe urban area, South West Province, Cameroon. Br J Ophthalmol 2007; 91(11): 1435-9.

17. Jeremiah N, Francis O, Alice O, Ibrahim M, Samson B, Mark $\mathrm{R}$, et al. Prevalence and Causes of Blindness and Low Vision in Southern Sudan. 2006; 12(3): 2417- 2443. e477 PLoS Medicine | www.plosmedicine.org.
18. Whitfield R, Schwab L, Ross-Degnan D, Steinkuller P, Swartwood J. Blindness and eye disease in Kenya: Ocular status survey results from the Kenya Rural Blindness Prevention Project. Br J Ophthalmol 1990; 74: 333-340. [PubMed]

19. Faal H, Minassian D, Sowa S, Foster A. National survey of blindness and low vision in the Gambia: Results. $\mathrm{Br} J$ Ophthalmol 1989; 73: 82-87. [PubMed]

20. Chirambo MC, Tielsch JM, West KP Jr., Katz J, Tizazu T, et al. Blindness and visual impairment in southern Malawi. Bull WHO 1986; 64: 567-572. [PubMed]

21. Tsai CY, Woung LC, Chou P, Yang CS, Sheu MM, Wu JR et al. The current status of visual disability in the elderly population of Taiwan. Jpn J Ophthalmol 2005; 49(2): 166-72.

22. Dineen B, Bourne RRA, Jadoon Z, Shah SP, Khan MA, Foster $A$ et al. Causes of blindness and visual impairment in Pakistan. The Pakistan national blindness and visual impairment survey. Br J Ophthalmol 2007; 91: 1005-1010.

23. Ereifej I, Zawaida F, Haddadin H. Causes of visual impairment and blindness among the middle-aged and elderly in northern Jordan. East Mediterr Health J 2002; 8(2-3): 404-8.

24. Zainal M, Ismail SM, Ropilah AR, Elias H, Arumugam G, Alias D et al. Prevalence of blindness and low vision in Malaysian population: results from the National Eye Survey 1996. Br J Ophthalmol 2002; 86(9): 951-956.

25. Xu L, Wang Y, Li Y, Wang Y, Cui T, Li J, Jonas JB. Causes of blindness and visual impairment in urban and rural areas in Beijing: the Beijing Eye Study. Ophthalmology. 2006; 113(7): 1134.e1-11

26. Iwase A, Araie M, Tomidokoro A, Yamamoto T, Shimizu H, Kitazawa Y. Tajimi Study Group. Prevalence and causes of low vision and blindness in a Japanese adult population: the Tajimi Study. Ophthalmology 2006; 113(8): 1354-62.

27. Buch H, Vinding T, Nielsen NV. Prevalence and causes of visual impairment according to World Health Organization and United States criteria in an aged, urban Scandinavian population: the Copenhagen City Eye Study. Ophthalmology 2001; 108(12): 2347-57.

28. Foster A. Cataract-a global perspective: output, outcome and outlay. Eye 1999; 13: 449-453.

29. Hennis A, Wu SY, Nemesure B, Honkanen R, Leske MC. Awareness of incident open-angle glaucoma in a population study: the Barbados Eye Studies. Ophthalmology 2007; 114(10): 1816-21.

30. Dandona R, Dandona L, John RK, et al. Awareness of eye diseases in an urban population in southern India. Bull WHO 2001; 79: 96-102.[Medline] 